\title{
A Guerra Fria e a final do Campeonato Mundial de Xadrez de 1972: algumas possibilidades analíticas e correlacionais
}

CDD. 20.ed. 796.05

796.53

\author{
Juliano de SOUZA ${ }^{* * * *}$ \\ Wanderley MARCHI JUNIOR ${ }^{* * * *}$
}

*Centro de Pesquisa em Esporte, Lazer e Sociedade, Universidade Federal do Paraná. **Asociación Latinoamericana de Estudios Socioculturales del Deporte - Brasil.

\section{Resumo}

Nesse artigo pretendemos esboçar uma possibilidade de leitura sociológica que contemple algumas das contingências socioculturais e políticas presente no campo de forças orientado pelo embate entre capitalistas e socialistas durante o período da Guerra Fria, procurando, na medida do possível, estabelecer algumas relações desse fenômeno com o campo esportivo e, mais especificamente, com a final do campeonato mundial de xadrez disputada pelo enxadrista soviético Boris Spassky e o enxadrista norteamericano Robert James Fischer em Reykjavik na Islândia no ano de 1972. Na primeira parte do texto, procuramos sugerir e evidenciar alguns pontos de aproximação passiveis de serem estabelecidos entre a estrutura microssociológica do "match do século" e a estrutura macrossociológica da Guerra Fria com base no referencial teórico de Norbert Elias. Em seguida, nos predispomos a explorar essas relações a partir do modelo de análise sociológica dos campos de Pierre Bourdieu.

Palavras-chave: Guerra Fria; "Match do século"; Xadrez; Sociologia do esporte.

\section{Introdução}

O período histórico-social denominando como Guerra Fria determinou a paisagem estratégica e o equilíbrio de forças no mundo por volta de aproximadamente 50 anos $^{1}$. Na tentativa de sistematizar uma definição que contemple os múltiplos aspectos sociais envolvidos nesse contexto, podemos dizer, de forma sintética, que a Guerra Fria tratou-se do embate político, econômico, tecnológico, científico, ideológico e cultural que se protagonizou entre o bloco capitalista e socialista durante o período compreendido entre o fim da Segunda Guerra Mundial em 1945 e a queda da União Soviética em 1991.

A denominação "Fria" se explica exatamente porque não se tratou de um confronto em que Estados Unidos e União Soviética - as duas principais nações que emergiram como superpotências após o término da Segunda Guerra - se envolveram direta e objetivamente nos campos de batalha, embora essa hipótese, durante esse período, tenha sido sempre uma constante e perigosa ameaça no universo das relaçōes internacionais ${ }^{2}$.

Muitos estudiosos com discussões expressivas no campo de produção historiográfica e sociológica têm se debruçado sobre a temática da Guerra Friaa ${ }^{1-16}$. No entanto, ainda há muitas rupturas, obscuridades e lacunas que precisam ser trazidas à tona sobre esse período histórico-social que, longe de se tratar de um recorte homogêneo e linear da história, representa muito mais um estágio de desenvolvimento social marcado pelas "incertezas" e pelos "rumores"16.

Segundo o historiador brasileiro Paulo VIZENTINI ${ }^{16}$ (p.195), a Guerra Fria tem sido estudada prioritariamente de duas formas: ou como prolongamento de um conflito de natureza ideológica, ou então, na condição de uma mera luta pelo poder entre duas superpotências. Não obstante, o que ambos os enfoques guardam em comum é o fato de priorizarem a dimensão militar-nuclear como eixo de análise, o que, em última instância, trata-se de uma postura que acaba representando uma distorção da realidade social, especialmente por desconsiderar uma gama de processos culturais, emocionais e simbólicos que se fizeram atuantes e decisivos no contexto desse embate.

Em afastamento a essas perspectivas, VIZENTINI ${ }^{15}$ propõe uma leitura histórico-social da Guerra Fria como um conflito de dimensão multifacetada, racionalmente 
explicável a partir das transformaçôes sociais que marcaram o século XX e que, sobretudo, sustentaram o desenvolvimento das relações internacionais no curso de uma história-social orientada e mobilizada basicamente em função das demandas internas das duas superpotências que insurgiram objetivamente após a Segunda Guerra.

Além disso, devemos frisar que uma das mais notórias particularidades analíticas de algumas das discussões historiográficas produzidas sobre a Guerra Fria é considerar que a mesma "[...] foi uma construção soviética, que queria expandir o comunismo para o resto do mundo [...]" ou então "[...] uma construção norte-americana, para justificar suas ações e consequentes intervenções nas nações que estivessem fora da 'esfera' do domínio soviético"13 (p.62-3).

No entanto, esses argumentos estão carregados de prenoções de pensadores ocidentais que, engajados na luta contra a expansão do comunismo, tendem a culpar exclusivamente os soviéticos pela Guerra Fria. Por outro lado, uma série de estudos produzidos nas viradas dos anos 1960 e 1970, defendem a ideia de que a gênese da Guerra Fria seria uma construção norte-americana, já que os soviéticos completamente abalados pela Segunda Guerra Mundial, não teriam por interesse investir de tal forma contra os Estados Unidos ${ }^{13}$.

É importante notarmos, que as explicações que comumente se desenvolvem na esteira dessas argumentaçôes, tendem a bloquear nosso acesso a uma série de fatores, fundamentos e desdobramentos sociais da Guerra Fria. Além disso, para entendermos a produção das crenças - e a Guerra Fria esteve arraigada num forte sistema de crenças $^{11}$ (p.123-8) - precisamos primeiramente romper com nossas próprias ideologias e prenoções herdadas do senso comum ou então expressas e legitimadas sob a forma de "bom senso científico".
Animados por esse espírito metodológico, pretendemos ao longo deste artigo esboçar uma possibilidade de leitura sociológica que contemple algumas contingências socioculturais e políticas presente no campo de forças orientado pelo embate entre capitalistas e socialistas durante o período da Guerra Fria, procurando, na medida do possível, estabelecer relaçôes desse fenômeno com o campo esportivo e, em seguida, com a final do campeonato mundial de xadrez disputada pelo enxadrista soviético Boris Spassky e o enxadrista norte-americano Robert James Fischer em Reykjavik na Islândia entre as datas de 11 de julho a $1^{\circ}$ de setembro de 1972 , num confronto que teve uma notória repercussão mundial e ficou conhecido como o "match do século".

Para tanto, nos valemos, do ponto de vista empírico, de uma série de materiais bibliográficos e jornalísticos que serão acionados e articulados mediante algumas indicaçōes teórico-metodológicas de Norbert Elias e Pierre Bourdieu, eleitos como interlocutores de nossa argumentação justamente por nos remeterem "[...] a conceitos e categorias explicativas das relações sociais que oferecem condiçōes de entendimento dos mecanismos objetivos de constituição e desenvolvimento da sociedade, sem negligenciar as importantes dimensões culturais e simbólicas da vida social"17 (p.32). O texto que segue se divide em dois momentos específicos. Num primeiro deles, temos por objetivo apresentar, a partir da Sociologia Configuracional de Norbert Elias, alguns pontos de aproximação que podem ser estabelecidos entre a estrutura microssociológica do "match do século" e a estrutura macrossociológica da Guerra Fria. Em seguida, predispomo-nos a explorar esse núcleo de relaçôes a partir do modelo de análise sociológica dos campos de Pierre Bourdieu.

\section{A Guerra Fria e o "match do século": um jogo político de interdependência}

Ao revisitarmos a "teoria do jogo competitivo" adotada pelo sociólogo alemão Norbert Elias como modelo de síntese heurística, ainda que tardio, da abordagem sociológica configuracional ${ }^{18}$, nos deparamos com a possibilidade metodológica de relacionarmos a Guerra Fria com um grande "jogo social" desde que, entretanto, consideremos o desenvolvimento do mesmo a partir de uma série de movimentos não planejados, dotados de significância histórica e, portanto, cruciais para compreender quais demandas sócio-políticas teriam polarizado União Soviética (URSS) e Estados Unidos (EUA) em um confronto que transcendeu aos "fronts" de batalha, ou melhor, que nem chegou a se delinear diretamente neles.

No bojo dessa análise, o historiador Paul KEN$\mathrm{NEDY}^{1}$, formula uma estrutura de análise políticoeconômica para contextualizar e explicar algumas das contingências que teriam colocado em movimento a chamada Guerra Fria. Para tanto, o autor se propõe a pensar e retomar uma série de eventos 
e fatores que vinham se desenhando nas políticas internas de Estados Unidos e União Soviética, assim como na ordem global anterior.

$\mathrm{Na}$ formulação dessa agenda, Kennedy enfatiza que durante o período da Segunda Guerra Mundial, as diferenças e tensōes político-ideológicas já existentes entre Estados Unidos e União Soviética, foram deixadas provisoriamente de lado, ante a necessidade de se unir forças para combater o nazismo e fascismo em ascensão $^{1}$ (p.355).

Com o fim da Segunda Guerra e a vitória dos Aliados (Estados Unidos, Grã-Bretanha e União Soviética) essas divergências políticas, econômicas, culturais e ideológicas foram trazidas à tona sob o rótulo distintivo do que ficou conhecido como Guerra Fria. Na compreensão do autor, a visão de harmonia, liberdade e paz mundial visada pelos Estados Unidos com o fim da Segunda Guerra ainda era comprometida pelo regime soviético.

Além disso, algumas posturas soviéticas desagradavam aos Estados Unidos, tais como, a eliminação da democracia na Polônia e na Tchecoslováquia; o desejo da elite soviética de isolar seus países satélites e seu povo das ideias e "riquezas" do Ocidente; enfim, a resistência soviética à influência norte-americana suscitada pela intensificação do papel da ideologia no interior do bloco socialista ${ }^{1}$ (p.349).

Eric HobSBAWM ${ }^{2}$, por sua vez, também se ateve à problemática da Guerra Fria. Em "A era dos extremos", o autor defende que esse período que vai desde o lançamento das bombas atômicas até a queda da URSS, não representou um período homogêneo, único e linear na história. Hobsbawm apresenta alguns argumentos importantes em seu texto. $\mathrm{O}$ primeiro deles seria a existência de no mínimo duas fases para a referida guerra - primeira Guerra Fria que transcorreu até aproximadamente 1970 e segunda Guerra Fria, demarcada a partir de 1970 até a queda do muro de Berlin e a desfragmentação da União Soviética.

Um segundo ponto enfatizado pelo autor é que a Guerra Fria possivelmente não se originou na Europa, mas nos Estados Unidos e em função do temor que o governo norte-americano tinha de uma expansão socialista pela Europa central e demais países. Outro aspecto que Hobsbawm aborda diz respeito ao constante estudo e atenção que uma potência exercia sobre a outra, sem a qual se inviabilizava jogar o jogo da corrida armamentista, tecnológica, científica, ideológica, dentre outras ${ }^{2,13}$.

Diante de tal conjuntura explicitada pelos autores, podemos entrever, portanto, que durante a Guerra Fria, Estados Unidos e União Soviética formaram aquilo que $\operatorname{ELIAS}^{18}$ (p.83), chama de interdependência funcional, isto é, uma configuração onde os movimentos de um grupo determinavam os movimentos do outro grupo e vice-versa. Um "lance" que potencialmente ilustra essa estrutura de dependência mútua foi, por exemplo, a retirada dos mísseis norteamericanos na Turquia no ano de 1962 e em resposta à desativação dos mísseis soviéticos instalados na Cuba de Fidel Castro no mesmo ano ${ }^{2}$ (p.227).

Entretanto, o que sobremodo, interessa destacar para a estruturação de nosso argumento, é que foi exatamente nesse cenário de lutas para equilibrar a balança de poder, ora pendida para o lado norte-americano, ora para o lado soviético, que se desenrolou o "match do século", ou seja, no período em que se iniciara a segunda fase da Guerra Fria por volta dos anos 1970. Vale ressaltarmos, que a própria denominação "match do século" é resultado de uma forte campanha midiática construída em torno do fato de Estados Unidos e União Soviética entrarem pela primeira vez frente a frente e fisicamente numa arena de guerra - a guerra simulada pelo jogo de xadrez.

Importante evocarmos aqui os aspectos miméticos e catárticos do jogo competitivo conforme sugeridos por Elias na parte introdutória do livro "A busca da excitação". Para o autor, quando os indivíduos se encontram em situações de jogo, lhes é permitido vivenciar uma luta sem tantos perigos físicos que uma batalha real representaria. Trata-se, portanto, daquilo que o sociólogo chamou de combates miméticos, isto é, "[...] confrontos realizados por meio do jogo num contexto que pode originar uma excitação agradável, desencadeada pelo combate, com o mínimo de ferimentos nos seres humanos"19 (p.95).

Assim sendo, o "match do século" pode ser encarado como um confronto mimético, ou seja, uma disputa revestida de toda uma indumentária simbólica e que possivelmente gerou nos indivíduos uma carga de excitação fornecida pelo quadro imaginário de uma guerra entre dois extremos, a qual não se realizou objetivamente nos "fronts" de batalha, mas em palcos alternativos. Dito de outro modo, o "match do século" se caracterizou, de fato, como uma guerra protagonizada em um tabuleiro de xadrez, ou melhor, um capítulo de uma guerra, já que o embate político entre capitalistas e socialistas também abrangera demais esportes, além de outros setores da vida social.

Quanto ao vínculo de interdependência social mantido entre o enxadrista norte-americano Bobby Fischer e o enxadrista soviético Boris Spassky, é imperativo notarmos que o mesmo não se limitou ao confronto protagonizado na Islândia em 1972. 
Pelo contrário, esse vínculo entre os dois jogadores se tratava, já naquela época, de uma contingência histórica, visto que eles já eram adversários antigos, tendo se enfrentado em outras cinco oportunidades, com três vitórias para Spassky e dois empates.

Não podemos perder de vista ainda, o fato de que os dois jogadores estudavam reciprocamente o repertório enxadrístico um do outro, o que também veio a caracterizar um grau de dependência mútua entre eles. Na preparação para o match sabe-se, por exemplo, que Spassky treinou cerca de quatro meses com sua equipe técnica fornecida pelo governo soviético, dentre os quais se incluía o grande mestre Efim Geller, ao passo que Fischer se dedicou individualmente ao estudo das partidas de seu adversário ${ }^{20}$.

Todavia, é importante lembramos que o mais significativo vínculo de aproximação estabelecido entre Fischer e Spassky foi caracterizado, de fato, durante o "match do século". E isso não simplesmente por se tratar de uma decisão de campeonato mundial, mas pelo fato de que os próprios países rivais a que ambos pertenciam terem se colocado nesta final a partir da figura dos dois jogadores em questão. Nesse sentido, faz-se necessário reiterar que os vínculos de interdependência não se evidenciam apenas nos casos de aliança, mas também quando grupos e indivíduos rivalizam. Com relação a isso, o próprio Elias esclarece:

No caso de um jogo de futebol, possivelmente, não é muito difícil reconhecer a interdependência dos adversários, a interligação das suas acções e, desse modo, o facto de os grupos rivais constituírem uma única configuração. Talvez, no tempo presente, seja muito mais difícil reconhecer isto na sociedade em geral, onde igualmente, numerosos grupos são totalmente interdependentes e na qual, também, as acçôes e sentimentos recíprocos não podem ser reconhecidos se não compreenderem os oponentes em causa como uma única configuração. A este respeito, talvez o exemplo mais elucidativo seja a corrida aos armamentos entre duas superpotências. É um exemplo de um processo autoperpetuado, o qual não pode ser compreendido se alguém tentar perceber cada um dos lados de maneira isolada, isto é, independentemente do outro. Nesta situação, o equivalente de um processo de jogo, a corrida em auto-escalada aos armamentos, tem, também, uma relativa autonomia em relação aos objetivos e intençôes dos grupos de dirigentes dos dois lados. Cada parte pode acreditar ser um agente livre, mas ambos são, de facto, cativos do processo de jogo que, também neste caso, provavelmente, toma um curso que não era intencional para nenhum dos $\operatorname{lados}^{19}$ (p.87-8).
Durante a Guerra Fria, a interdependência funcional e estrutural mantida entre Estados Unidos e União Soviética foi uma constante. Os vínculos possibilitados não no sentido de unir forças, mas de medir forças se confirmava a cada novo "lance" realizado no grande "tabuleiro social". Como exemplo dessa trama, podemos citar o fato de que, ao fim da Segunda Guerra, tanto a União Soviética quanto os Estados Unidos reduziram mutuamente seus exércitos, a fim de evitar dispêndios e investimentos desnecessários.

Entretanto, quando uma das potências demonstrava abrir uma vantagem numérica e qualitativa na produção de armamentos e demais produtos belicosos, a outra remanejava seus investimentos em pesquisa e aumentava a cota de produção interna desses equipamentos de guerra ${ }^{1}$. Além disso, devemos destacar no âmago desse processo, o importante papel desempenhado pelos serviços secretos de informação de ambos os blocos e sem o qual se impossibilitava conhecer os passos do adversário, seu potencial de investimento bem como o ritmo de produção armamentista ${ }^{2,16}$.

Na oportunidade do mundial de 1972, os laços objetivos de interdependência entre os dois lados haviam se estreitado mais ainda, haja vista, por exemplo, que nesse período, segundo observa HoBSBAWM ${ }^{2}$, além das inúmeras negociações políticas protagonizadas entre os dois países, o uso da famosa linha vermelha - sistema de telefonia que ligava o Kremlin à Casa Branca - havia se intensificado. Além disso, a ideia do tabuleiro de xadrez como simulacro de um confronto político e militar foi levado muito a sério pelas duas superpotências. Nesse particular, é importante lembrarmos que, desde 1940, Estados Unidos e União Soviética usavam uma espécie de protótipos do que viriam a ser os programas de computadores (que hoje conhecemos) para simular confrontos nucleares ${ }^{21-22}$.

Quanto ao "match do século", a aspiração norteamericana possivelmente era desbancar a URSS de um dos postos que ainda mantinha sob sua hegemonia após a Segunda Guerra. É oportuno notarmos que a maestria do xadrez sempre esteve associada à inteligência, o que no contexto da Guerra Fria implicaria em associar a nação que viesse a ser derrotada como "menos inteligente" 22 . Por sua vez, tais disseminações ideológicas, dentre outras, se faziam possíveis graças ao papel desempenhado pelos meios de comunicação de massa.

Outras situações também corroboram para avaliarmos o envolvimento do governo norte-americano e soviético na final do campeonato mundial de xadrez de 1972. É sabido, por exemplo, que quando Fischer se indispusera a continuar o "match" contra 
Spassky, Henry Kissinger - conselheiro do presidente norte-americano Richard Nixon - telefonou pedindo-lhe que não desistisse do campeonato, pois se tratava de algo muito importante para a nação norte-americana ${ }^{23}$ (p.210).

Por outro lado, quando Fischer já caminhava a "passos largos" para a conquista do título mundial com 10,5 a 7,5 em seu favor, Sergei Pavlov - presidente da comissão oficial de desportos da URSS em nível de ministério - recomendou, em duas oportunidades, que Spassky abandonasse a decisão do mundial e regressasse ao seu país em protesto as injúrias do norte-americano durante o decorrer do campeonato $^{23}$ (p.292-3).
Evidente que as possibilidades analíticas não se esgotam nesses exemplos rapidamente evocados. Entretanto, tais situaçôes evidenciadas são bastante pontuais e úteis para ilustrar algumas das estratégias utilizadas, consciente ou inconscientemente, pelo bloco soviético e norte-americano no sentido de procurar manter o equilíbrio estável da balança de poder na configuração social que ambos os países e seus aliados compunham na arena internacional. Em outras palavras, se tratam de situações que nos permitem inferir que a gênese do embate entre o sistema capitalista e socialista se deu preliminarmente no interior do campo político e econômico e se legitimou nos campos de produção dos bens culturais e simbólicos, como veremos a seguir.

\section{A repercussão da Guerra Fria nos campos de produção cultural e no campo esportivo}

A reconstrução dos Estados europeus, após a Segunda Guerra Mundial, foi financiada basicamente com o dinheiro norte-americano visando, sobretudo, impor uma política de protecionismo econômico e de expansão dos mercados ${ }^{16}$. Dito de forma mais precisa, depois da Segunda Guerra acentuou-se as dificuldades financeiras principalmente na Europa, visto que os países pertencentes a essa região do globo haviam sofrido grande desgaste econômico nesse período, restando-lhes aderir à economia de importação oferecida pelos EUA, a qual, em última análise, levou-os Estados europeus a exaustão de suas reservas monetárias.

Entretanto, devemos notar que essa expansão do mercado norte-americano na Europa não foi aceita pacificamente e, pelo contrário, foi contraposta, primeiro, pelas tendências democratizantes dos denominados movimentos antifascistas que conferiram representatividade aos grupos políticos de esquerda e, segundo, pela existência de vias nacionais autônomas tanto no oeste como no leste europeu ${ }^{15}$.

O governo norte-americano percebendo e notando a ação diretiva e opositiva desses movimentos, oportuna e imediatamente proclamou a Doutrina Truman e, em seguida, lançou o Plano Marshall. A implementação dessas políticas se deu no ano de 1947. A Doutrina Truman foi lançada e legitimada através de um discurso do presidente norte-americano Harry Truman, no qual o mesmo defendia o auxílio dos Estados Unidos aos países europeus que estivessem sob ameaça de regimes considerados totalitaristas e opressores. O Plano Marshall, por sua vez, era um programa pelo qual se concedia empréstimos aos países europeus com taxas de juro relativamente baixas para que, em seguida, exportassem mercadorias norte-americanas ${ }^{1}$.

Importante frisarmos que o contraponto econômico da aceitação dessas políticas era considerável, já que as nações que se beneficiassem desse crédito deveriam abrir suas economias aos investimentos norte-americanos, o que, no caso das economias fracas (em especial as do leste europeu) ou devedoras (mais precisamente, as dos países do ocidente europeu) representava abandonar parte de sua soberania demarcada de forma histórica e estrutural no universo das relações internacionais.

Some-se a essa análise o fato de que tais planos previam o aprofundamento da divisão de trabalho entre o ocidente europeu que centrava sua economia na indústria e o leste europeu que devia seu desenvolvimento econômico, até aquele momento, especialmente à agricultura $^{2,16}$. Pautados nessas implicaçôes e demandas, tanto a União Soviética quanto os países sob seu raio de influência recusaram-se a aceitar a ajuda norteamericana, percebida, pelo contrário, como uma invasão econômica que conduziria à perda de autonomia e representatividade no campo político e econômico.

Diante dessa conjuntura explicitada, podemos dizer, portanto, que a Doutrina Truman e o Plano Marshall lançaram as bases materialistas para a divisão da Europa em dois blocos político-militares. No entanto, apenas a inserção e imposição dessas políticas ainda não seriam suficientemente representativas para demarcar a abertura e instituição da Guerra Fria. 
Além disso, a crença socialmente partilhada em torno do antifascismo e do pacifismo conforme previsto no Tratado de Yalta - acordo pós-guerra estabelecido entre Churchill, Roosevelt e Stalin em 1945 -, representava um contraponto ideológico de grande significância à implementação de uma nova guerra tão próxima da que, há anos antes, havia deixado a estrutura social e econômica europeia completamente fragmentada e destruída ${ }^{1}$.

Dito de outro modo e fazendo uso das palavras do historiador Paulo VIZENTINI ${ }^{16}$ (p.200), para que a Guerra Fria, de fato, pudesse se estruturar de maneira incisiva no universo das relações internacionais "[...] era preciso lançar mão de poderosos mitos e imagens, que desarticulassem essa corrente e condicionassem a população a uma visão maniqueísta”. Daí a necessidade, sobretudo do bloco ocidental e capitalista, de estender e legitimar essa disputa no interior dos campos de produção dos bens culturais. Nesse sentido, os meios de comunicação, a arte e, em específico, o esporte foram "locus" e instrumentos pelos quais tanto os Estados Unidos quanto a União Soviética procuraram projetar ao mundo uma determinada proposta de sociedade "ideal".

No que se refere aos meios de comunicação, ou melhor, às tomadas de posição dos agentes no interior do campo midiático, as estratégias utilizadas pelos dois blocos político-econômicos visavam, primeiramente, mobilizar a opinião pública em favor de um dos sistemas e, em seguida, "demonizar" o concorrente ${ }^{7,13}$. É oportuno notarmos que nos Estados Unidos, os meios de comunicação não funcionavam sob o controle do Estado, o que, por sua vez, não significa que as implicações de ordem política se faziam ausentes no campo. Já na União Soviética, os meios de comunicação foram utilizados como um aparelho ideológico de Estado controlado rigorosamente pelo partido comunista.

Nas produçôes culturais divulgadas e vendidas nos países de economia capitalista eram feitas constantes alusóes anticomunistas que circulavam tanto de forma explícita quanto velada através dos mais variados veículos e plataformas de informaçãa ${ }^{24}$. Todavia, temos a impressão de que esse uso político dos produtos e bens culturais no interior dos mais distintos campos não foi calculado e projetado conscientemente pelos agentes e estruturas responsáveis pela produção dos referidos bens e práticas, o que, por sua vez, não significa que os mesmos eram passivos diante das dinâmicas socioculturais e políticas associadas à Guerra Fria.

Além disso, devemos frisar que no ocidente divulgava-se e veiculava-se, através da venda de produtos e bens culturais, a imagem dos comunistas como "máquinas" a serem vencidas: fortes, frios e calculistas, incapazes de sorrir ou então expressar qualquer traço humanista. Um interessante exemplo desta caricaturização do "indivíduo do outro lado" é o filme "Rocky IV" de produção norte-americana e no qual o personagem soviético representava uma verdadeira "máquina assassina", enquanto o norteamericano prestativo e sensível lutava avidamente para vingar a morte de seu amigo, morto no ringue pelo boxeador soviético ${ }^{25}$.

Por outro lado, as ações políticas do governo soviético, expressas através da produção de bens culturais e artísticos foram direcionadas, impreterivelmente, para dentro dos Estados socialistas, ressaltando, sobretudo, sua superioridade frente ao imperialismo capitalista a partir do discurso sobre a inevitável vitória do comunismo na tessitura social mais ampla. Valores pautados no otimismo, nacionalismo, sucesso do regime, ameaça exterior e produtividade foram temas invariavelmente enfatizados ${ }^{25}$.

Cabe ainda lembramos a importância da propaganda para o regime socialista como arma de divulgação dos valores estatais. Por sua vez, a disseminação desses ideais e crenças se davam, sobretudo, a partir da ação diretiva e militante dos integrantes do Partido Comunista com vistas à difundir homogeneamente a doutrina ao longo das teias sociais e politizar o bloco como uma massa popular uniforme ${ }^{26}$.

A produção artística soviética também foi fortemente influenciada e direcionada pelo sistema comunista. A "arquitetura imponente" e as "esculturas colossais" dos líderes e trabalhadores soviéticos tinham, segundo Noam CHOMSKY ${ }^{26}$, a função de impor a imagem desses agentes ao povo na condição de autoridades oficiais indiscutíveis. Exemplo dessa inserção se deu, de modo mais incisivo, durante o governo de Stalin, quando o realismo soviético nas artes e o culto à personalidade do estadista se estabeleceram como as estratégias de maior destaque e eficácia. Quanto à mídia soviética, é importante frisarmos que a mesma filtrava as notícias internacionais e reiterava o papel soviético no contexto mundial, tendo também o intuito de politizar a população conforme a doutrina regente do partido comunista.

Essas disputas, por sua vez, não se limitavam apenas ao raio de ação do campo midiático e artístico. Dentre outros espaços sociais, o campo esportivo também foi palco do embate entre capitalistas e socialistas. A propósito, podemos dizer que os Jogos Olímpicos de Helsinque de 1952 foi o primeiro grande evento esportivo no qual os dois 
blocos político-ideológicos procuraram demonstrar a superioridade de um regime ao outro através do desempenho dos seus atletas, dos resultados obtidos nos estádios, ginásios e piscinas, da distribuição das medalhas e, principalmente, do uso midiático do desempenho esportivo dessas duas nações e, é claro, dos demais países influenciados diretamente por seus sistemas políticos ${ }^{27}$.

É sempre bom lembrarmos que a União Soviética iniciou sua participação em Jogos Olímpicos exatamente na edição de Helsinque em 1952. Na edição de 1948 em Londres, a nova potência mundial optou por não comparecer e, dessa forma, não medir forças com a hegemonia esportiva norte-americana expressa no campo esportivo, sobretudo, através da performance de seus atletas nos esportes olímpicos. Ao invés de participar, a União Soviética resolveu enviar um corpo de especialistas para analisar os atletas e os métodos de treinamento adotados pelos países capitalistas. Nos anos que se seguiram, o governo soviético destinou grandes recursos a projetos de massificação e especialização esportiva, visando formar atletas de alto nível que representassem a ideologia comunista nos jogos ${ }^{27,28}$.

Entretanto, o retorno material e simbólico esperado pelo regime comunista só veio nos Jogos Olímpicos de 1956 em Melbourne, quando a União Soviética conseguiu superar os Estados Unidos no número de medalhas de ouro/prata/bronze e, por conseguinte, no número total de medalhas. $\mathrm{Na}$ edição dos jogos de 1960 em Roma, novamente a União Soviética repetiu o feito. Já nos Jogos Olímpicos de Tóquio e Cidade do México, realizados respectivamente em 1964 e 1968, os Estados Unidos recuperou o posto de primeiro lugar no quadro geral de medalhas. A União Soviética, nas duas ocasiōes, ficou em segundo lugar, tendo, sobretudo, somado mais medalhas que os Estados Unidos na edição dos Jogos realizados em Roma ${ }^{28}$.

Nos Jogos Olímpicos de 1972 em Munique, a União Soviética terminou em primeiro lugar com 17 medalhas de ouro a mais que os Estados Unidos que ficou na segunda colocação. Em 1976, nos Jogos de Montreal, não apenas a União Soviética se colocou na frente dos Estados Unidos, mas também a Alemanha Oriental que, a propósito, também era controlada pelo regime comunista soviético. Em 1980, os Jogos Olímpicos foram realizados em Moscou, e os Estados Unidos por questōes aparentemente políticas resolveu boicotar essa edição dos jogos juntamente com mais 61 países que aderiram ao apelo do presidente norteamericano Jimmy Carter.
A justificativa de ordem política para a boicotagem desses países aos jogos de Moscou se deu especificamente pela invasão das forças soviéticas ao Afeganistão em dezembro de 1979. Entretanto, também é importante buscarmos outros motivos para explicar o referido boicote a partir da história estrutural relativamente autônoma do esporte - isto é, daquelas contingências históricas referentes ao mundo esportivo que não se constituem num mero reflexo das lutas travadas e acumuladas no campo político e econômico ${ }^{29-30}$-, já que os Estados Unidos muito provavelmente não ultrapassaria a União Soviética em número de medalhas de ouro, pelo fato de que a estrutura esportiva soviética, naquele momento, talvez estivesse mais bem preparada e, além disso, porque a URSS era anfitriã dos jogos, o que potencialmente maximizaria mais ainda o desempenho de seus atletas.

Em 1984, na edição dos Jogos Olímpicos de Los Angeles, foi a União Soviética, Alemanha Oriental, Cuba e demais países sob a zona de influência comunista que resolveram boicotar os jogos. Não obstante, o boicote do bloco soviético teve menor abrangência devido a uma grande campanha iniciada anos antes pelo Comitê Olímpico Internacional (COI), e que, dessa forma, havia convencido muitos países a participarem dessa edição dos Jogos Olímpicos ${ }^{27,31}$. Um dado interessante, a ser lembrado dos Jogos Olímpicos de Los Angeles é o fato do mesmo ter sido o primeiro na história a ser financiado majoritariamente pela iniciativa privada, demonstrando ao mundo que a relação entre esporte e as grandes corporaçôes é eficaz e proporciona grandes espetáculos ${ }^{27}$.

Finalmente em 1988 na cidade de Seul, as duas potências tornaram a se enfrentar pelos Jogos Olímpicos. Na oportunidade, a União Soviética conseguiu conquistar 19 medalhas de ouro a mais que os Estados Unidos que ficou em terceiro lugar, atrás ainda da Alemanha Oriental. Nos Jogos Olímpicos de 1992 realizados em Barcelona, a URSS, já então desintegrada, competiu representando a Comunidade dos Estados Independentes (CEI) e fechou em primeiro lugar no "ranking" de medalhas, seguida pelos Estados Unidos que ficou com a segunda colocaçãa ${ }^{28}$.

De forma bastante sintética, essas são algumas das principais tensōes protagonizadas no interior do campo midiático, artístico e esportivo por conta da Guerra Fria. No que se refere às tomadas de posição político-ideológicas reverberadas no universo de concorrência esportiva, devemos frisar que embora o confronto olímpico seja alusivo e esclarecedor sobre as dimensões simbólicas e emocionais que cercearam 
o embate entre socialistas e capitalistas durante o período da chamada Guerra Fria, é importante lembrar que a disputa travada por Estados Unidos e Uniāo Soviética no campo esportivo não se resumiu única e exclusivamente à agenda dos Jogos Olímpicos.

Colocado sob outro aparato conceitual, o embate entre o sistema capitalista e socialista durante esse período de aproximadamente 50 anos também foi protagonizado em outros eventos esportivos, deixando marcas tão profundas na história social do esporte quanto àquelas que foram construídas e constituídas por ventura e pela ocasião dos Jogos Olímpicos. É sobre algumas dessas dimensões e desdobramentos que iremos nos debruçar nas próximas páginas.

\section{A Guerra Fria e as disputas materiais e simbólicas no subcampo esportivo do xadrez}

Em conformidade com a discussão empíricoteórica até aqui empreendida, é possível avançar no tratamento do "match do século" protagonizado no subcampo esportivo do xadrez em 1972 como um exemplo desses eventos com conotação políticoideológica que se legitimaram no interior do campo esportivo de modo a direcionar as tomadas de posições dos agentes segundo as sanções do mercado e segundo a lógica das disputas travadas no campo político. Vejamos algumas dessas implicaçóes:

Em primeiro lugar, devemos lembrar os esforços políticos que foram realizados para que Bobby Fischer pudesse disputar o torneio interzonal de Palma de Mallorca em 1970 e, consequentemente, o torneio de candidatos em 1971, sem os quais o mesmo não poderia ter conquistado o direito de ir à final contra Spassky. Oficialmente, os classificados para disputar o torneio interzonal de 1970 representando os Estados Unidos foram os enxadristas William Addison, Samuel Reshevsky e Paul Benko que haviam conquistado as vagas no torneio zonal norte-americano um ano antes.

No entanto, é imperativo frisar que apesar desses enxadristas supracitados se distinguirem, de fato, como jogadores de alto nível, os mesmos, objetivamente falando, não tinham grandes condições de desbancar Spassky e conquistar o título mundial para os Estados Unidos ${ }^{32}$. Amparado nesse raciocínio o coronel Edmund B. Edmondson - diretor executivo da federação norte-americana de xadrez - convenceu Fischer, que estava "inativo" há 18 meses, a retornar aos torneios de xadrez. Uma segunda medida tomada por Edmondson foi articular uma estratégia de negociação para que Fischer pudesse disputar o torneio interzonal.

Convicto de que a Fédération International des Échecs (FIDE) já havia cedido a muitas reivindicações de Fischer, Edmondson primeiramente propôs que o enxadrista fosse incluído no próximo interzonal por se tratar do jogador número um do "ranking" norteamericano - sistema que inclusive a FIDE mais tarde admitiria para realizar uma classificação mundial dos jogadores $^{33}$ (p.67). No entanto, essa proposta não foi aceita. Então Edmondson realizou outra proposta, que consistia na possibilidade de desistência de um dos classificados no torneio zonal norte-americano de modo que Fischer viesse a ocupar essa vaga. Nesse caso, a FIDE não apresentou objeções.

Restava agora a Edmondson convencer um dos três enxadristas norte-americanos classificados para o torneio interzonal de desistir de sua participação e ceder o posto a Bobby Fischer. Por uma boa compensação oferecida pela federação norte-americana de xadrez, Paul Benko acabou aceitando a proposta ${ }^{32}$ (p.135). No entanto, alguns anos mais tarde Benko declarou que a ideia dessa troca havia sido arquitetada por ele e que jamais teria feito isso por outro jogador senão Fischer, afinal acreditava que somente esse enxadrista tinha possibilidades reais de conquistar o inédito título para os Estados Unidos ${ }^{34}$ (p.110).

O torneio interzonal de Palma de Mallorca - uma ilha localizada na Espanha - foi realizado entre os dias 8 de novembro e 13 de dezembro de 1970 . Grandes nomes do xadrez mundial participaram do referido torneio, dentre os quais, Efim Geller, Vasily Smyslov, Mark Taimanov e Lev Polugaievski da União Soviética, Lajos Portisch da Hungria, Bent Larsen da Dinamarca, Wolfgang Uhlmann da Alemanha Oriental, Robert Hübner da Alemanha Ocidental, Svetozar Glicoric da Iugoslávia, Henrique da Costa Mecking do Brasil, além é claro, de Bobby Fischer que foi o vencedor e a grande sensação do torneio ${ }^{33-34}$ (p.68-9 e p.111, respectivamente).

Os seis primeiros colocados no torneio interzonal de Palma de Mallorca foram, respectivamente, Fischer, Larsen, Geller, Hübner, Taimanov e Uhlmann. Em 1971, esses enxadristas juntaram-se ao ex-campeão mundial Tigran Petrosian e a Viktor Kortchnoi - finalista 
no torneio de candidatos de 1968 - para disputarem o torneio de candidatos que revelaria o adversário de Spassky em 1972. O primeiro desafiante de Fischer nesse torneio qualificatório para disputa do título mundial foi o soviético Mark Taimanov. O referido match correspondente então às quartas-de-final do torneio de candidatos foi realizado na cidade canadense de Vancouver em uma série melhor de 10 partidas, sendo que o jogador que somasse primeiramente 5,5 pontos estaria apto a avançar às semifinais.

Por um placar de 6 a 0 Fischer desbancou Taimanov. A repercussão desse resultado foi bastante negativa na União Soviética. Placar igual a esse só havia se construído na "história esportiva" do xadrez em 1876 quando Steinitz venceu Blackburne por 7 a 0 em um "match" histórico realizado na cidade de Londres ${ }^{33}$ (p.71). Ao retornar a seu país, Taimanov teve que dar explicaçôes oficiais ao Comitê de Educação Física e Esportes - órgão equivalente aos demais ministérios estatais controlados pelo Partido Comunista na União Soviética.

Como medida punitiva para o mau desempenho apresentado pelo enxadrista soviético diante do adversário norte-americano na competição, o ministro de Educação Física e Esportes, Sergei Pavlov, sugeriu que fosse retirado seu título de grande mestre. Todavia, isso não foi possível e Pavlov foi advertido de que não era competência do governo soviético dar ou retirar tais títulos de um jogador. Como consequência política de sua derrota, Taimanov teve então seus bens e patrimônios confiscados, além de ter sido proibido de dar concertos por tempo indeterminado em seu país e no exterior ${ }^{34}$ (p.117).

Nas semifinais do torneio de candidatos, o adversário de Fischer foi o dinamarquês Bent Larsen que havia vencido Uhlmann em seu match de quartas-de-final. Após acordos entre os jogadores, suas respectivas federações e a FIDE, o lugar escolhido para celebração do "match" foi a cidade norte-americana de Denver. Larsen também foi derrotado por Fischer pelo placar de 6 a 0. Depois do encontro, Larsen declarou que em Denver fazia um excessivo calor e a altitude da cidade era muito elevada, o que, segundo o enxadrista, comprometeu seriamente seu desempenho. Seu grande equívoco insistiu Larsen, foi ter aceitado jogar na cidade que havia sido sugerida pelo norte-americano ${ }^{33}$ (p.73).

Após sua classificação invicta para a final do torneio de candidatos, Fischer recebeu a seguinte carta do presidente norte-americano Richard Nixon:

Quería añadir mis felicitaciones personales a las muchas que ya habrá recibido. Su racha de de diecinueve victorias consecutivas en una competición mundial carece de precedentes, y tiene todos los motivos para sentirse muy satisfecho de su soberbio logro. Mientras se prepara para enfrentarse al ganador del encuentro entre Petrosian y Korchnoi, no le quepa duda de que sus compatriotas le estarán dando ánimos. ¡Buena suerte. ${ }^{134}$ (p.119).

Interessante notar nessa fala traços de um "habitus" nacionalista norte-americano equivalente a relativa posse de um capital simbólico adquirido no espaço das tomadas de posições no campo esportivo e, mais especificamente, naquele momento histórico, no subcampo esportivo do xadrez. Esse trecho também corrobora no entendimento de que enfrentar a União Soviética em um esporte que há algumas décadas vinha representando a ideologia comunista e, além disso, com possibilidades reais de vitória, era algo dotado de enorme significância política e simbólica nos Estados Unidos.

Avançando na exposição dos argumentos, convém frisarmos que a final do torneio de candidatos também se revestiu de certa indumentária simbólica e mimética. Segundo os pesquisadores e periodistas da BBC Londres, David EDMONDS e John EIDINOw ${ }^{34}$ (p.120), esse "match" protagonizado entre o enxadrista soviético (armênio) Tigran Petrosian e o enxadrista norteamericano Bobby Fischer foi um prelúdio do circo midiático de Reykjavik. O encontro entre Petrosian e Fischer foi realizado, a saber, na cidade de Buenos Aires, embora durante as negociações o enxadrista soviético tivesse insistido para jogar na cidade de Atenas. Todavia a capital argentina, havia oferecido mais dinheiro e melhores condiçóes para realizar o "match" do que a capital grega. Sob essa circunstância, os dois jogadores bem como suas federaçōes e a FIDE optaram pela oferta argentina, escolha essa, é sempre bom lembrar, que coincidia mais incisivamente com as tomadas de posição de Fischer ${ }^{33-34}$.

Buenos Aires era uma das capitais do xadrez mundial, com cerca de 60 clubes funcionando e oferecendo essa prática à população local e, principalmente, aos aficionados. Para organizar o "match" foram oferecidos sete mil e quinhentos dólares para o vencedor e quatro mil e quinhentos dólares para o perdedor. O confronto disputado em melhor de 12 partidas teve lugar no Teatro General San Martín - centro da vida cultural citadina e localizado na famosa Avenida Corrientes, a Broadway argentina ${ }^{33-34}$ (p.73 e p.120, respectivamente).

Seria considerado vencedor o enxadrista que antes somasse 6,5 pontos. Ao término da quinta partida, o "match" estava empatado por 2,5 a 2,5 
com uma vitória para cada lado e três empates. No entanto, as quatro próximas partidas foram vencidas por Fischer que assim conquistou o direito de no ano seguinte disputar a final do título com o atual campeão mundial Boris Spassky.

Em 3 de janeiro de 1972 foram então iniciadas as negociações para a realização do "match" entre Spassky e Fischer. A primeira medida tomada pela FIDE foi estabelecer um consenso juntamente com os dois enxadristas finalistas e suas respectivas federaçōes, sobre a escolha da cidade-sede para o evento. Spassky elaborou uma lista elencando as quatro cidades de sua preferência: Reykjavik, Amsterdam, Dortmund e Paris. Fischer procedeu do mesmo modo e sugeriu as seguintes cidades: Belgrado, Sarajevo, Buenos Aires e Montreal.

Como podemos perceber as listas elaboradas pelos jogadores, de fato, eram bem distintas. Diante desse impasse, o presidente da FIDE, Max Euwe, propôs no dia 14 de fevereiro de 1972 que o "match" fosse realizado em duas cidades: a primeira série de 12 partidas em Belgrado e a segunda série de 12 partidas em Reykjavik ${ }^{35}$. Cabe notarmos que a proposta não agradou a nenhuma das cidades apontadas. Em Reykjavik, a preocupação era que um dos jogadores conseguisse tal vantagem de pontos na primeira parte do "match" que quando o campeonato fosse transferido para Islândia, o resultado já seria irreversível. Em Belgrado, por sua vez, a preocupação era que a melhor e mais lucrativa parte do "match" seria realizada em Reykjavik ${ }^{32,34}$.

Finalmente, em 20 de março de 1972 esse acordo foi formalizado em reunião presidida na cidade de Moscou com os representantes da federação soviética, norte-americana, islandesa e iugoslava de xadrez, além é claro, dos representantes da FIDE. No entanto, alguns dias depois, o enxadrista Bobby Fischer enviou uma carta recusando o acordo assinado por Edmondson, e na qual ameaçava não comparecer ao "match" caso não se modificassem os acordos econômicos de modo que todos os ingressos dos campeonatos, descontando os gastos, fossem revertidos para os jogadores, além de uma cota dos direitos televisivos ${ }^{34}$ (p.154-5).

Perplexos com essa situação, os organizadores iugoslavos pediram uma garantia de 35 mil dólares para a realização dos jogos, já que as frequentes exigências e o histórico de faltas de Fischer em torneios poderiam comprometer o andamento e, até mesmo, a realização e continuidade do "match". Todavia, a federação norte-americana de xadrez era uma associação amadora que não tinha receita própria e, muito menos, condições autônomas para levantar essa quantia exigida. Os soviéticos, por sua vez, não demonstraram nenhuma objeção ao pagamento desse valor e assentiram ao pedido iugoslavo. Edmondson apresentou resistências e insistiu que qualquer garantia desse gênero era ilegal, o que, em última análise, levou os iugoslavos a retirarem sua oferta para sediar o "match"34 (p.155).

Então se desencadeou um novo trâmite e Reykjavik assumiu a função de organizar o confronto por completo. O presidente da federação islandesa Gudmundur Thorarinsson acreditava que o referido confronto não apenas seria o "match do século", mas o "match" de todos os tempos. É importante frisarmos que os esforços de Thorarinsson para que a Islândia organizasse o "match" não era um ato desinteressado. Pelo contrário, seu objetivo principal se constituía em aproveitar a oportunidade do match para lançar as bases de uma futura e possível carreira política em seu país ${ }^{34}$.

Thorarinsson viu esse ideal político ser comprometido, quando as vésperas da realização da cerimônia oficial de abertura do "match", soube que o enxadrista Bobby Fischer ainda não havia chegado à Islândia. Seu receio era ser lembrado como organizador de um "match" que não aconteceu. De fato, o cerimonial de abertura do "match" foi realizado sem a presença do enxadrista norte-americano no dia $1^{\circ}$ de julho de 1972 , às oito horas da tarde no Teatro Nacional de Reykjavik ${ }^{33}$.

A primeira partida do confronto estava marcada para dia 2 de julho às 5 horas da tarde no Palácio de Esportes Laugardals-Hollei. Quando faltavam duas horas para que se iniciasse a partida, o presidente da FIDE Max Euwe, já informado de que Fischer não compareceria ao jogo, convocou uma coletiva à imprensa e declarou oficialmente que se o norte-americano não chegasse à Islândia até o meio-dia do dia 4 de julho, o "match" estaria cancelado e Spassky retornaria a Moscou para defender seu título diante de Petrosian ${ }^{35}$.

No entanto, não foram essas as circunstâncias e ameaças que fizeram Fischer mudar de ideia. Além do telefonema especial de Henry Kissinger, pedindo para que o enxadrista reconsiderasse sua posição em honra aos Estados Unidos, a oferta do banqueiro londrinense Jim Slater de dobrar a premiação do "match" de 125 mil dólares inicialmente oferecidos pela Islândia para 250 mil dólares, contrabalançou a situação de modo que Fischer se predispôs a tomar um avião de Nova York e por volta das sete da manhã do dia 4 de julho desembarcar no Aeroporto Internacional de Reykjavik para jogar o "match" contra Spassky ${ }^{32,36}$ (p.79 e p.13, respectivamente).

Euwe concedeu uma semana de adiamento ao "match" por conta de reivindicaçôes da equipe 
soviética. Nesse meio tempo, Fischer aproveitou para pedir desculpas oficiais a Spassky através de uma carta enviada ao hotel em que o jogador se hospedava. Nessa semana de folga, ainda veio uma notícia de Moscou na qual se alegava que um computador seria usado em Nova York para ajudar Fischer, de modo que receberia as jogadas, calcularia e, em seguida, retornaria o melhor lance a ser executado pelo enxadrista norte-americano ${ }^{37-38}$.

No entanto, essa hipótese foi tida como ridícula, afinal, em 1972, os computadores ainda tinham pouca capacidade de processamento e jogavam muito pior do que qualquer mestre. Seria preciso aguardar 25 anos até que o programa "Deep Blue" da IBM (International Business Machines) vencesse Garry Kasparov $^{22,39}$. Cabe aqui notarmos que por mais descabidas que fossem tais alegações e especulações, as mesmas eram muito comuns e rotineiras no universo em questão, povoando o imaginário popular e constituindo uma "doxa" bastante rentável a ser noticiada e vendida pela imprensa escrita e televisionada.

No dia 11 de julho de 1972, finalmente, iniciouse então a disputa para definir o título de campeão mundial de xadrez. Spassky venceu a $1^{\mathrm{a}}$, a $2^{\mathrm{a}}$ e a $11^{\mathrm{a}}$ partida. Fischer, por sua vez, venceu a $3^{a}$, a $5^{a}$, a $6^{a}$, a $8^{a}$, a $10^{a}$, a $13^{a}$ e a $21^{\text {a }}$ partida. Os demais jogos terminaram empatados totalizando 11 partidas. A $21^{\text {a }}$ partida que consagrou Fischer como campeão mundial de xadrez se realizou no dia 31 de agosto de 1972.

Convém reiterar que esse período de quase dois meses foi caracterizado por muitas indisposiçōes de ordem política, sobretudo, do lado soviético. A partir do momento em que Fischer tomou a frente no "match" na sexta partida, Spassky e sua equipe receberam orientação do Comitê de Educação Física e Esportes da União Soviética para que não fizessem mais nenhuma concessão a Bobby Fischer. Contudo, o ápice desse embate simbólico se deu logo após a $17^{\text {a }}$ partida realizada no dia 22 de agosto, quando os dirigentes da equipe soviética acusaram os norteamericanos de estarem usando dispositivos eletrônicos e uma substância química para enfraquecer Boris Spassky ${ }^{32-33}$.

No dia seguinte, os organizadores islandeses convocaram dois estudiosos locais detentores de relativo capital científico - Dadi Augustin e Sigmundur Gudbjarnason - para averiguarem o cenário em que o match estava sendo protagonizado. A cadeira de Fischer e a iluminação do palco também foram alvos das análises ${ }^{34}$. No entanto, o ponto incisivo desse episódio se deu quando Augustin adentrou ao local de jogo, sacudiu um saco plástico no interior da sala em que se realizavam as partidas, e em seguida selou-o, escrevendo numa etiqueta: "Ar do palco". O laudo final dessa inspeção sugeriu a presença de duas moscas mortas no equipamento luminoso, o que provocou hilaridade por parte da imprens $\mathrm{a}^{34,37,40}$.

Cabe, no entanto, ressaltar que essas especulações político-ideológicas não se restringiram apenas ao "match do século", já que no torneio de candidatos que precedeu esse confronto, Fischer também foi acusado de possuir "poderes sobrenaturais" e utilizar de hipnose contra seus adversários, afinal a derrota de Taimanov e Larsen sem ganhar sequer uma partida dele, era tida no senso-comum como algo improvável e impossível a não ser que estratégias ilícitas estivessem em jogo. O comentário do enxadrista e jornalista português João Cordovil ilustra bem o que estamos dizendo:

Não é a primeira vez que "Bobby" Fischer sofre deste tipo de acusaçóes. No "match" precedente contra Tigran Petrossian, é o grande mestre Miguel Najdorf que nos conta, nos comentários que faz à segunda partida deste encontro, o seguinte diálogo: "Meio a sério, meio a brincar, Rona, esposa de Petrossian, perguntou-me, no dia anterior, se Fischer não teria oculto consigo algum computador electrónico que lhe ditasse as jogadas. Eu ri, mas ela insistiu. Não se ria que pode ser verdade". O norte-americano perdeu essa partida e Najdorf intitulava o seu artigo, ironicamente, de "O computador em mau dia". Os soviéticos há muitos anos que se preocupam com Fischer. Pode o leitor estar seguro de que o estudaram de todas as formas possíveis e imaginárias. Não correriam o risco de o deixar chegar até à final, se houvesse alguma suspeita de hipnotismo...23 (p.224).

Outro comentário sugestivo sobre essas forças "ocultas" ou ilícitas supostamente atuantes e decisivas nas vitórias de Bobby Fischer sobre Spassky e sobre os demais enxadristas soviéticos é fornecido por Edmonds e Eidinow:

La vigilancia existía antes del match, tal como prueba el informe oficial al Comité de Deportes sobre la preparación de Spassky, redactado el 16 de octubre de 1971 por Víktor Baturinski. En el informe advertía de que los norteamericanos intentarían celebrar el match en el continente americano, lo cual conferiría a Fischer "ciertas ventajas" El informe continuaba: "Además, en la relación con los resultados de los matches de Fischer contra Taimanov, Larsen e Petrosian, existen algunas conjeturas sobre la influencia en estos resultados de factores ajenos al ajedrez (hipnosis, telepatía, comidas drogadas, escuchas de análisis internos, etc.)". Tras la aplastante derrota de Taimanov, el director de 
su equipo, Alexandr Kotov, suscitó el tema de las influencias externas ajenas al ajedrez sobre Spassky: "Da la impresión de que esto no es la primera vez que sucede. En el match entre Taimanov e Fischer, tuve la sensación todo el tiempo de que había gente escuchándonos" ${ }^{34}$ (p.288).

Nunca é demais lembrar que do lado dos produtores do espetáculo, esse tipo de especulações expressava no fundo o desejo dos agentes envolvidos justificarem seus fracassos e maus desempenhos no subcampo do xadrez e no campo esportivo, atribuindo essas condiçôes, na maioria das vezes, à causas terceiras ou então à tomadas de posições que justamente feriam a lisura esportiva. Já do lado dos consumidores do espetáculo, essas suspeições e crenças tinham objetivamente por intuito fundar um universo de representaçóes que conferisse um maior valor simbólico-emocional às práticas e bens consumidos e, de forma indireta, aos seus próprios estilos de vida.

Essa tessitura empírico-teórica, por sua vez, também sugere que a disputa daquele título para o bloco comunista era fundamental e importante na trama político-simbólica em questão, afinal as inúmeras e consecutivas vitórias que a União Soviética havia conseguido perpetuar no subcampo do xadrez desde 1948 confirmavam, segundo a crença nacionalista difundida no país, a superioridade do sistema soviético sobre os Estados Unidos em termos de solicitação das faculdades intelectuais e desenvolvimento cultural, industrial, tecnológico e esportivo ${ }^{22}$.

Não obstante essas conjecturas, é oportuno ressaltar que a vitória do enxadrista Robert James Fischer quebrando uma hegemonia soviética de 24 anos no subcampo esportivo do xadrez trata-se de algo potencialmente explicável através da noção de autonomia relativa do esporte, pensada por BouRDIEU $^{29-30}$, para ponderar o fato de que campo esportivo possui sua própria cronologia, especificidades e que, portanto, não deve ser retomado e perspectivado a partir somente da influência de fatos políticos e econômicos. Esse direcionamento, no entanto, não quer dizer que as relaçôes estruturadas em torno do "match do século" e, de uma forma mais ampla, em torno da própria "história esportiva" do xadrez não estejam intimamente associadas ao que ocorreu no universo das relações sociais mais amplas e no contexto econômico e, sobretudo, político. As próprias análises desenvolvidas ao longo do texto dão conta, inclusive, de demonstrar algumas maneiras pelas quais o esporte se interrelaciona com a política e com a economia.
Nesse sentido, inclusive, é que nos aprouve evocar a noção bourdieusiana de história relativamente autônoma do esporte para aventar e estruturar a hipótese de que a vitória do enxadrista norte-americano sobre o enxadrista soviético se fez devedora, acima de tudo, à diferença de preparação técnica, tática e psicológica entre os dois concorrentes sob as circunstâncias sociais evidenciadas na referida oportunidade e, deste modo, não se devia a fatores externos ao referido confronto (suborno, corrupção, utilização de substâncias químicas para enfraquecer o oponente etc.). Por sua vez, só trouxemos esse fato no presente momento, para que a carga mimética, simbólica e dramática associada ao contexto do "match do século" por parte dos produtores e consumidores do espetáculo não fosse antecipadamente desfeita, secundarizando então a importância de se revisitar e se referendar a trama simbólico-emocional relacionada ao domínio da Guerra Fria para explicar alguns dos processos e algumas das dinâmicas de oferta e consumo esportivo presentes nesse contexto de disputas político-ideológicas evidenciadas.

Em que pese essa leitura, não podemos negar, no entanto, a existência de implicações políticas e relações de favorecimento no campo esportivo interferindo no resultado dos certames, muito embora sejamos inclinados a crer que no interior dessa conjuntura simbólica atuante no espaço dos esportes, se prefiguram mais traços característicos e identificadores de uma denominada "teoria da conspiração" do que propriamente de um cálculo prospectivo e racionalista dos produtores esportivos de modo a prescrever os resultados e a transcorrência do jogo, se bem que não se pode descartar que as tentativas do "corpus" de especialistas burocráticos em subverter as regras sempre rondam, de forma perigosa e questionável, os eventos protagonizados no campo esportivo.

Essa "teoria da conspiração", por conseguinte, não é boa e nem má. Fruto de disposiçôes históricas, ela está a se perpetuar e se reproduzir no campo esportivo revestida das mais distintas formas miméticas e catárticas quando senão dessas variantes combinadas. Além disso, é exatamente por via dessas especulações suscitadas que se constitui uma das especificidades em voga nas práticas esportivas e que, inclusive, lhes tornam atrativas e lhes predispõem como um locus de visibilidade e lucratividade das mais diversas sintonias, qual seja, e em uma só palavra, o sensacionalismo.

Com relação, portanto, ao universo representacional constituído em torno do "match do século", é importante ressaltar que se, de antemão, houvéssemos 
ignorado o contexto histórico de disputas objetivas e simbólicas erguido entre os Estados Unidos e a União Soviética no período da Guerra Fria, muitos detalhes e informaçôes cruciais para análise que propomos nos seriam bloqueados, se bem que a explicação para a vitória do enxadrista norte-americano sobre o enxadrista soviético, como já dissemos, não pode ser deduzida das impressōes primeiras dos agentes de modo a se concordar então que os fatores que concorreram para o resultado desse confronto eram de ordem eminentemente político-ideológica como assim se foi feito crer em diversas instâncias.

Em contrapartida, se centrássemos nossa abordagem em demonstrar e avaliar as diferenças técnico-táticas que fizeram Fischer sobrepujar a Spassky nesse contexto, fugiríamos ao escopo que originalmente animou o estudo que deu origem a este artigo ${ }^{41}$, qual seja o de sustentar e endossar o argumento de que a cristalizaçâo do subcampo do xadrez no campo esportivo nos anos 1970 - isto é, a consolidação de uma estrutura de oferta e consumo da modalidade no universo de concorrência esportiva - se deu mediante a imposição de um arbitrário cultural pautado nas disputas simbólicas entre as duas superpotências como realidade fundadora de um universo consumista de disposições midiáticas revestidas de contornos políticos.

Nesse particular, insistimos e defendemos que a retomada do período histórico-social da Guerra Fria é importante para as análises sociológicas do esporte porque a mesma nos possibilita recuperar e, em seguida, entender alguns dos sentidos da oferta esportiva produzidos na sociedade do consumo e do espetáculo. Conforme tentamos aqui demonstrar, esses sentidos específicos da oferta esportiva nesse contexto histórico-social relativamente particular foram construídos de duas formas complementares.

Primeiramente, devemos notar que o embate entre Estados Unidos e União Soviética favoreceu a disseminação, em larga escala, do modelo de vida consumista norte-americano para várias regiôes do mundo ${ }^{16}$. E isso, sobretudo, pelas vias mais insidiosas possíveis, quais sejam, as que solicitam irrefletidamente o imaginário dos agentes e suas emoções, o que, em termos mais sucintos, nos sugere uma constituição simbólica e emocional do mercado.

Um segundo ponto de sustentação para pensarmos o esporte a partir dessa incursão histórico-estrutural no contexto da Guerra Fria diz respeito ao fato de que o conjunto de crenças que veio a consolidar aquilo que estamos chamando de "teoria das conspirações" no campo esportivo foram ressignificadas e encontraram as condições sociais favoráveis para sua cristalização durante esse período de aproximadamente meio século. Dito de outro modo, sem esse pano de fundo simbólico e consensual, muitas das especulações cotidianas e midiáticas produzidas, por exemplo, em relação aos Jogos Olímpicos (especialmente a edição de Moscou e Los Angeles) ou então sobre o "match do século" dificilmente seriam digeridas e repercutiriam em escala global.

No entanto, na consolidação desse processo, os agentes e estruturas inerentes ao raio de ação do campo midiático concorreram de forma singular no interior do universo que eles próprios constituíam de modo a possibilitar a circulação e difusão homogênea desses valores perpassados pelo simbolismo da Guerra Fria, valores esses que, diga-se de passagem, haviam encontrado oportunamente no confronto entre "Fischer-Spassky" um "locus" social apto a materializar no contexto dos anos 1970 a dimensão desse embate entre as duas potências nascido objetivamente no interior do campo político.

Além disso, é necessário atentar ao "insight" empírico-teórico de que enquanto algumas ideias e representações presentes no imaginário social têm sua gênese, de fato, nas lutas intrínsecas garantidas pela relativa autonomia que cabe ao subcampo do xadrez, outras ideias e representações são produzidas pioneiramente pelos intelectuais e agentes midiáticos e a partir do raio de ação desses atores é que se espalham e se enraízam no senso comum.

Por sua vez, o desvelamento dessa tendência de circulação social das ideias e das representações nos interessa, sobretudo, porque a mesma é que nos permitiu avaliar, do ponto de vista das necessidades psicossociais dos agentes, a lógica de concorrência da modalidade de xadrez - prática esportiva fundada em esquemas simbólicos e miméticos decorrentes de seu caráter historicamente relacional traçado com a guerra e, em função do contexto histórico-estrutural que evocamos, com a própria Guerra Fria - no interior do campo esportivo, especialmente, durante o "match do século" quando em função de todos esses elementos simbólico-emocionais em jogo a modalidade adquiriu uma maior visibilidade mundial e protagonizou a "fase de ouro" de sua "história esportiva". 


\title{
Nota
}

a. Como exemplo dessa tendência ver: WESSON ${ }^{42}$.

b. Dentre outros trabalhos, podemos citar: DeUTSCHER ${ }^{3}$ e KOLKO ${ }^{4}$.

\begin{abstract}
The Cold War and the World Chess Championship final in 1972: some analytical and correlational possibilities

In this article we intend to outline a possible sociological point of view wich contemplates some contingencies socio-cultural and political contingencies present in the field driven by the struggle between capitalists and socialists during the Cold War, trying to establish some associations between this phenomenon and the sports field, and more specifically, with the final of the chess world championship involved the Soviet Boris Spassky and the American Robert James Fischer, undertaken in Reykjavik (Iceland) in 1972. In the first section, we suggested and highlighted some points of convergence that can be established between the structure of microsociological "match of the century" and the macrosociological structure of the Cold War based on the theoretical framework of Norbert Elias. Afterwards we these relationships were explored taken into account the model of sociological analysis of the fields of Pierre Bourdieu.
\end{abstract}

KEY WORDS: Cold War; "Match of the century"; Chess; Sociology of sport.

\section{Referências}

1. Kennedy P. Ascensão e queda das grandes potências: transformação econômica e conflito militar de 1500 a 2000. Rio de Janeiro: Campus; 1991.

2. Hobsbawm E. A era dos extremos: o breve século XX: 1914-1991. São Paulo: Companhia das Letras; 1995.

3. Deutscher I. Mitos da Guerra Fria. In: Horowitz D, organizador. Revolução e repressão. Rio de Janeiro: Zahar; 1969.

4. Kolko G. The limits of power. New York: Harper \& Row; 1970.

5. Leuchtenburg WE. Cultura de consumo e Guerra Fria. In: Leuchtenburg WE. O século inacabado: a América desde 1900. Rio de Janeiro: Zahar; 1976.

6. Delmas C. Armamentos nucleares e Guerra Fria. São Paulo: Perspectiva; 1979.

7. Castoriadis C. Diante da guerra: as realidades. São Paulo: Brasiliense; 1982.

8. Thompson EP. Beyond the cold war. London: Merlin Press; 1982.

9. Thompson EP. Notas sobre el exterminismo, o estágio final da civilização. In: Thompson EP. Exterminismo e Guerra Fria. São Paulo: Brasiliense; 1985. p.3-31.

10. Thompson EP. Os fins da Guerra Fria: uma resposta. In: Blackburn, R, organizador. Depois da queda. Rio de Janeiro: Paz e Terra; 1993. p.73-85.

11. Elias N. Condição humana. Lisboa: Difel; 1985.

12. Chomsky N. Novas e velhas ordens mundiais. São Paulo: Scritta; 1996.

13. Biagi OL. O imaginário da Guerra Fria. Rev Hist Reg. 2001;6:61-111.

14. Gaddis, J. L. História da Guerra Fria. Rio de Janeiro: Nova Fronteira, 2006.

15. Vizentini PF. Da Guerra Fria à crise 1945-89. Porto Alegre: UFRGS; 1996.

16. Vizentini PF. A Guerra Fria. In: Reis Filho DA, Ferreira J, Celeste Z, organizadores. O século XX. 4a ed. Rio de Janeiro: Civilização Brasileira; 2008. p.195-223.

17. Marchi Júnior W, Souza J. Norbert Elias e Pierre Bourdieu: tensões e conversações teórico-metodológicas no exercício de compreensão do mundo social. In: Bourguignon JA, Oliveira Junior CR, organizadores. Pesquisa em ciências sociais: interface, debates e metodologias. Ponta Grossa: Todapalavra; 2012. p.31-47.

18. Elias N. Introdução a Sociologia. Lisboa: Edições 70; 1980.

580 • Rev Bras Educ Fís Esporte, (São Paulo) 2013 Out-Dez; 27(4):567-81 
19. Elias N. Introdução. In: Elias N, Dunning E. A busca da excitação. Lisboa: Difel; 1992. p.39-99.

20. Lasker E. História do xadrez. 2a ed. São Paulo: IBRASA; 1999.

21. Saidy A. The battle of chess ideas. London: Batsford; 1972.

22. Johnson D. White king and red queen: how the Cold War was fought on the chessboard. London: Atlantic Books; 2007.

Lancelotti S. Olimpíada 100 anos: história completa dos Jogos. São Paulo: Nova Cultural; 1996.

23. Cordovil J. Diário Popular (cobertura do mundial de xadrez de 1972). In: Trifunovicth P. Fischer-Spassky: Pelo ceptro do xadrez. Lisboa: Presença; 1973.

24. Arbex Júnior J. Guerra fria, terror de estado, política e cultura. São Paulo: Moderna; 1997.

25. Cruz MAS, Pontes R, Maia RC. Propaganda e guerra fria. Rio de Janeiro: Núcleo de Estudos Contemporâneos/UFF; 2005. (Grandes Processos).

26. Chomsky N. Controle da mídia: os espetaculares feitos da propaganda. Rio de Janeiro: Graphia; 2003.

27. Sigoli MA, De Rose Júnior D. A história do uso político do esporte. Rev Bras Ciênc Mov. 2004;12:111-9.

28. Cardoso M. Os arquivos das olimpíadas. São Paulo: Panda; 2000.

29. Bourdieu P. Como é possível ser esportivo? In: Bourdieu P. Questôes de sociologia. Rio de Janeiro: Marco Zero; 1983. p.136-53.

30. Bourdieu P. Programa para uma sociologia do esporte. In: Bourdieu P. Coisas ditas. São Paulo: Brasiliense; 1990. p.207-20.

31. Rubio K. Jogos Olímpicos da era moderna: uma proposta de periodização. Rev Bras Educ Fís Esporte. 2010;24:55-68.

32. Bjelica D. Reyes del ajedrez: Bobby Fischer. Madrid: Zugarto Ediciones; 1992.

33. Moran P. "Bobby" Fischer: su vida y partidas. Barcelona: Ediciones Martinez Roca; 1972.

34. Edmonds D, Eidinow J. Bobby Fischer se fue a la guerra: el duelo de ajedrez más famoso de la historia. Buenos Aires: Debate; 2007.

35. González JM. (...) Y ahora "Bobby Fischer Campeón del mundo. Rev Jaque. 1972:(Edición especial).

36. Segal AS. Campeonato mundial: Fischer x Spassky. São Paulo: Brasiliense; 1972.

37. Fine, R. The world's great chess games. New York: Dover; 1983.

38. Lima R. "Quando éramos reis, bispos, cavalos...”. Digestivo cultural, 9 abr. 2002. [citado 5 jun. 2008]. Disponível em: http://www.digestivocultural.com/colunistas/coluna.asp?codigo=493.

39. Giusti P. História ilustrada do xadrez. São Bernardo do Campo: Paulo Giusti; 2002.

40. Lima R. "Ar do palco ou xadrez nos tempos da Guerra Fria”. Digestivo cultural, 16 abr. 2002. [citado 5 jun. 2008]. Disponível em: http://www.digestivocultural.com/colunistas/coluna.asp? codigo=493.

41. Souza J. O xadrez em xeque: uma análise sociológica da "história esportiva" da modalidade [dissertação]. Curitiba (PR): Universidade Federal do Paraná, Departamento de Educação Física; 2010.

42. Wesson RG. A nova política externa dos Estados Unidos. Rio de Janeiro: Zahar; 1978.

\begin{tabular}{r|r} 
ENDEREço & \\
Juliano de Souza & \\
Universidade Federal do Paraná & Recebido para publicação: 03/02/2012 \\
Setor de Ciências Biológicas & Revisado: 17/03/2013 \\
Departamento de Educação Física & Aceito: 21/05/2013 \\
R. Coração de Maria BR 116, km 95 n.92 & \\
80215-370 - Curitiba - PR - BRASIL & \\
e-mail: julianoedf@yahoo.com.br &
\end{tabular}

Rev Bras Educ Fís Esporte, (São Paulo) 2013 Out-Dez; 27(4):567-81 • 581 